\title{
Community Based Networks and 5G
}

\author{
Idongesit Williams
}

Centre for Communications, Media and Information Technology,

Department of Electronic Systems, Aalborg University,

Copenhagen, Denmark

E-mail: idong@es.aau.dk

Received 21 February 2016;

Accepted 6 March 2016

\begin{abstract}
The deployment of previous wireless standards has provided more benefits for urban dwellers than rural dwellers. 5G deployment may not be different. This paper identifies that Community Based Networks as carriers that deserve recognition as potential $5 \mathrm{G}$ providers may change this. The argument is hinged on a research aimed at understanding how and why Community Based Networks deploy telecom and Broadband infrastructure. The study was a qualitative study carried out inductively using Grounded Theory. Six cases were investigated. Two Community Based Network Mobilization models were identified. The findings indicate that $5 \mathrm{G}$ connectivity can be extended to rural areas by these networks, via heterogenous networks. Hence the delivery of $5 \mathrm{G}$ data rates delivery via Wireless WAN in rural areas can be achieved by utilizing the causal factors of the identified models for Community Based Networks.
\end{abstract}

Keywords: 5G, Community Based Networks, telecom infrastructure, telecom services, CBNM models.

\section{Introduction}

This paper discusses the potential relationship between rural Community Based Networks and 5G infrastructure and service diffusion and adoption.

Journal of NBICT, Vol. 1, 105-122.

doi: 10.13052/NBICT.2016.006

(C) 2016 River Publishers. All rights reserved. 
The implication of this paper is to raise the awareness of the Community Based Networks as potential market players in the potential 5G market. Their potential does not lie in the facilitation of gateway networks to their communities. Rather, their potential lies in extending the access connectivity of 5G data rates and capacity using Wireless Local Area (WLAN) networks to their homes. Based on this awareness, the thought could go into developing proposed $5 \mathrm{G}$ antenna that can be deployed with high throughput WLAN antennas in a heterogenous network. An example of such WLAN interface is the 802.11 ac also known as $5 \mathrm{G} \mathrm{Wi-Fi}$. This will enable these community networks participate in the deployment of $5 \mathrm{G}$ datarates and capacity in rural areas.

Community Based Networks are not often mentioned as telecoms market player or telecom carriers. They are often viewed as localized groups with lack of technical expertise or financial capacity to facilitate telecoms network development [1]. Though this assertion may be true when it comes to deploying telecom standards with high deployment costs, this is not so when it comes to the deployment of Wireless Local Area Network (WLAN) Solutions such as the set of 802.11 standards. This is not totally true as well when it comes to the deployment of rural telephony in countries like Argentina and North America [2]. Hence, one cannot overlook the potential of these carriers to facilitate and deliver telecom network services when developing standards and services for $5 \mathrm{G}$.

The advantage of having these players is that they are not profit making entities [3]. Their existence is aimed at delivering telecom infrastructure in rural areas, that are not commercially viable. They are democratically goverened and these entities are open to recovering their operational cost on the long run $[2,4]$. So far, research has shown that these group are more inclined to deploying the 802.11 standards $[3,5]$. Hence, this inclination is one of the inspirations driving this paper.

To buttress the argument on the potentials of these carriers, a study was carried out in six on such carriers from different countries in the world at CMI, Aalborg university. These carriers were the Djurslandsnet (Denmark), Magnolia Road Internet Coop (USA), Hallaryd Broadband Coop (Sweden), Johanesburg Wireless User Group (South Africa), Ghana Wireless project (Ghana) and the Dharamsala Wireless Network (India). Aside the Hallaryd Broadband Coop, who facilitated Fibre-to-the-Home (FTTH), the other cases deployed Wireless Broadband solutions delivered via the 802.11 sets of standards. The Grounded Theory approach was adopted to identify causal factors that led to the facilitation of the Broadband infrastructure and services. This study provided an outlook on why and how Community Based Networks 
in developed countries and developing countries facilitate the deployment of affordable broadband networks and the adoption of the emerging services.

Based on this outcome, this paper proposes the study of the $5 \mathrm{G}$ needs of rural areas as well as the development of certain $5 \mathrm{G}$ standards, by which Community Based Networks can adopt. In this manner, 5G services would not be a luxury good to rural dwellers but a basic good as well.

\section{The Concept of 5G}

$5 \mathrm{G}$ is a standard mobile Wireless telephony defined differently by different organizations [6]. The ITU, METIS, Korea 5G Forum and the China future Forum define $5 \mathrm{G}$ as a mobile cellular technology providing a minimum of $1 \mathrm{~Gb} / \mathrm{s}, 10 \mathrm{~Gb} / \mathrm{s}, 50 \mathrm{~Gb} / \mathrm{s}$ and $10 \mathrm{~Gb} / \mathrm{s}$ respectively [6]. These organizations aside the ITU are organizations made up of collaborations between mobile industry players, the academia and public policy makers. These collaborations are aimed at developing standards as well as design the $5 \mathrm{G}$ ecosystem (See $[7,8])$.

$5 \mathrm{G}$ is a wireless technology, that is under development and in some cases undergoing trials. It is still unclear, whether $5 \mathrm{G}$ will be an upgrade of $4 \mathrm{G}$ or a new mobile technology [9]. However, Examples of such trials include the test of 5G Networks in Northern Groningen in the Netherlands and the trials by Verizon in partnership with Ericsson, Intel, Nokia and Samsung in the United States $[10,11]$. The test in Groningen was conducted by Huawei in partnership with Ericson.

However, though these aforementioned activities exist, the vision for the application of $5 \mathrm{G}$ is broad and diverse. The vision ranges from the technical specification of $5 \mathrm{G}$, the service expectations to the business models needed to sustain the ecosystem. From the technical perpective, aside the data rates expected from $5 \mathrm{G}$, spectral efficieny, signalling efficiency, latency in connectivity between humans and machines are important parameters [6]. The services vision include artificial intelligence complementing human to human communications [12]. The business models is being developed by organizations such as 5GPPP, etc. [7].

This vision, in part, is based on the improved technical performance of the upgrades of current Wireless WAN and WLANs. It is also based on the current possibilities presented by heterogenous networks. Mobile cellular technologies, as we know them today, are traditionally Wireless WANs. However, Wireless WAN solutions such as $3 \mathrm{G} / 4 \mathrm{G}$ could be interfaced with WLANs as heterogenous networks to deliver Internet services using micro 
and pico cells (See $[13,14])$. The possibility of heterogenous networks is not limited to these two technologies. They are used as an example for the purpose of this paper. The possibility of heterogenous networks has resulted in upgrades in both mobile cellular standards and Wireless LAN standards (such as 802.11) over time [15]. In recent times the 802.11 antennas and routers have been configured to deliver higher throughput [16]. Some brands such as Huawei have branded such routers as 4G Wi-Fi [17]. In 2013, IEEE developed the 802.11ac standard. The WLAN standard is transmited with the throughput $6 \mathrm{GHz}$ [18]. This standard is otherwise known as 5G Wifi [19]. Though there are other 802.11 standards designed to operate at other frequencies and different antenna coding requirements, the standard expected to directly succeed the 802.11ac are the 802.11ad (WiGig) and the 802.11ax standards [20, 21]. 802.11ax standard is expected to deliver 4 times the throughput of the 802.11 ac standard.

Hence based on the vision of what $5 \mathrm{G}$ should be and the possibility of deploying heterogenous wireless networks with $5 \mathrm{G}$ technical specifications, there is no technical specification for 5G. However, in this paper, the reference to $5 \mathrm{G}$ is on a wireless technology providing a data rate of minimum $1 \mathrm{~Gb} / \mathrm{s}$. More emphasis is placed on 5G Wi-Fi. This is because Community Based Networks find it easier to deploy the antennas for this technology.

\section{Community Based Networks and Telecom Infrastructure Development}

In this section, what is meant by a Community Based Network in this paper is defined. This is followed by the provision of insights into why such networks exist and how they are organized. The insights are derived from Community Based Networks that existed in the case study areas for the provision of telephony and Broadband infrastructure.

\subsection{Community Based Networks}

Community Based Networks are often an association of individuals who are poised to facilitate and democratically manage an Information Communication and Technology (ICT) enterprise [4]. The enterprise of interest in this paper is that which is concerned with the facilitation of telecom infrastructure. Although one cannot overlook the fact that Community Based Networks can also be centered around community computing - as this was the case as the internet evolved [22]. 
The individuals - who form a Community Based Networks - are believed to be galvanized by economic, social and cultural needs [4]. However, in other cases, they are galvanized by an existing market failure [23]. In certain cases the infrastructure can be developed and service delivered, but very few of the members will have a need for it. This implies that Community Based Networks do not necessarily serve everyone in the community. Rather, the organizational arrangement is based on the concept of the "organization of the willing". This raises the critical question of "what service will be of use to rural dwellers?" to foster all inclusiveness? This is a question that should not be neglected in the development of 5G.

Although cases of non-adoption of the current telecom and Broadband service exist, these cases could also be that the non-users will show as late adopters. Such users often join the band wagon much later, once they see the need [2]. If they exist in a social circle, where the service is adopted, then the potential of network effect prompts them to use the services. This phenomenon outlines the importance of revealing the actual need for the service or "usefulness" of the service to the individual.

Based on the aforementioned, it is safe to say that Community Based Networks are inspired by the potential of the service to the members of the network. At the dawn of the 20th Century, when voice telephony was the innovation of the day, network effect provided via voice telephony was a driver towards the development of telephony Community Based Networks. In recent times, the promise and actualization of Internet Protocol (IP) services delivered via Broadband now serve as a driver for the Broadband Community Based Networks. This is what makes a research into relevant $5 \mathrm{G}$ services to rural communities in countries where $5 \mathrm{G}$ will be prevalent, necessary.

Although, the potential of the service, to the Community Based Network owners did play a major role in the facilitation of these networks, there were also other reasons for the existence of these networks. These reasons did affect how these Community Based Networks are organized.

\subsection{Community Based Networks and Telephony Infrastructure Development}

Community Based Networks delivering telephony were rare on a global scale. However, in North America, Argentina and some parts of Europe, initiatives did exist $[4,24]$. Some of such initiatives have metamorphosed into Community Broadband networks, Broadband cooperatives and Local Internet Service providers serving the rural areas they belong to. A couple of examples 
include Brook Telecom in Canada and Adams Telephone Cooperative in the United States. Brook Telecoms was established in 1911 [25]. Adams Telephone Coop established in 1952 [26].

Both examples among hundreds of others were established as rural telephony Cooperatives. Their aim was to facilitate the establishment of rural telephony in their rural areas, as they were not being served by the market. These cooperatives were democratically organized. The positive aspect of their organization was the flexibility to change with the times. This enabled the cooperatives to facilitate improved telecom and now IP solutions to the rural areas they served.

Telephone Community Based Networks, did possess the hallmarks for the adoption of the telephony service as mentioned in the previous section in this paper. They desired utility services in general, but their dream was hampered by the Great depression of the 1930s. The crippling effect of the depression on western economies prompted the formation of cooperatives to provide the needed social amenties [27]. It was during this period that one can see the acceleration in the formation of telephony coops in the United States and Canada [2].

The formation of coops did not only provide the potential for an innovative economic structure in the development and management of the telephony infrastructure, it also provided an opportunity for the members to learn about the technology. Complex technical details, with time, became easy to grasp for the Community Based Networks. Hence, with time, private contractors were replaced by volunteers who learnt on the job. This led to job creation opportunities.

\subsection{Community Based Networks and Broadband Infrastructure Development}

The presence of the Community Based Networks aimed at facilitating Broadband infrastructure and services is not rare globally. In Sub-Saharan Africa, very few of such initiatives have survived [2], except for South Africa. The surviving initiatives in South Africa were facilitated by people groups or cooperates such as Johannesburg Wireless user Group, Pretoria Wireless User Group, etc. - to mention a few. The ones that did not survive are those that were introduced by International Donor Agencies. A third case involves some form of hybrid ownership between the public sector, the private sector and people groups. Some of these cases are relaxed cases. An example is the the Serengeti Broadband Networks in Tanzania are relaxed cases. 
In the Americas and in Europe, lots of such cases abound [24-28]. Some of these cases exist in urban neighborhoods, while others exist in rural areas. In the urban centers neighbors in certain buildings, where there

is a lack of Internet Access, form democratic associations to facilitate the service [29]. In other cases, citizens of region, municipality, urban or rural area, organize themselves into cooperatives to facilitate the Broadband infrastructure of their choice [2]. In some third cases, these cooperatives facilitate such infrastructure development in partnership with the municipality [30-32]. In other cases, technical expertise is outsourced to the private sector. These arrangements are mostly aimed towards wireless Broadband delivery overlaying fiber optic connectivity. In yet other cases, mostly in the EU, these Community Broadband Networks facilitate FTTH. However the tilt towards the deployment of WLAN solutions and in rare cases 802.16 Broadband Wireless Access standards, is an indication that if certain 5G standards are designed for deployment by Community Based Networks, then rural users will benefit from $5 \mathrm{G}$ services as well. The people in rural areas will enjoy higher data ratesbetter throughput, low latency and better Quality of Service. This will enable them enjoy bandwidth intensive services such as Voice over Internet Protocol (VoIP), Internet Protocol (IPTV) services and relevant over the top services. Companies in rural areas will be able to save cost of commuting for meetings by using either VoIP or, if they can afford it, Video conference services.

One would say again, that, based on the perceived usefulness of the service, people groups have found themselves to become Broadband infrastructure carriers. As such, to enable the sustainability of the network, these people groups develop unique business models to facilitate the inclusion of every member and would be members.

Here, again just as in the case of telephony delivery, one could see the boldness of members of Community Based Networks attempting to deploy a telecom infrastructure and service. This is mainly because they see the need for the services provided by the network.

\subsection{The Implication of 5G to Community Based Networks}

It is impossible not to foresee certain areas where market limitations will occur in the deployment of any $5 \mathrm{G}$ infrastructure and services. This will be glaring in rural areas. This is because, as mentioned, earlier, in the delivery of heterogenous 5G networks, there will be access technologies that will be pervasive to our daily lives. One of such wireless technologies will be 
Wireless Personal Access Networks (WPAN). These WPANs require sensors. The acquisition and maintenance of these sensors will have its own financial implications to the end user. If the end user does not find the service useful to his or her daily life, then subscribing to the service will be difficult.

Rather than promote every access network that can enable the delivery of $5 \mathrm{G}$ services, this paper proposes the WLAN for the communities. Based on research, it has been identified that Community Based Networks possess the potential to facilitate user trust for the service, if they facilitate the network development. These networks are operated using democratically agreed business models, the end user can trust - as they are not profit making entities. The end-user also possesses a sense ownership of the network and service. Hence what may be important would be to deliver certain 5G standards, by which the Community Based Network can find attractive to adopt. This will serve as a stop gap measure for market limitation in underserved areas.

If inspiration is to be gathered from the role of Community Based Networks in facilitating previous telecom infrastructures, then four things stand out. These issues are:

- Cost of deployment of infrastructure.

- Cost of end-user equipment.

- Usefulness of service.

- Sustainable business model.

If this is juxtaposed with the development of the infrastructure and services for 5G standard, what would be important for a start would be the cost of deployment of the service and the cost of end-user equipment. If the service is useful, but the aforementioned costs are high, then the likelihood adoption is low. If the adoption is low, then there may be no room for a sustainable business model by the Community Based Networks. The low cost of the equipment for such $5 \mathrm{G}$ standards would be facilitated possibly by:

- Its Spectral efficiency.

- Lower frequency allocation.

This will enable the infrastructure to deliver coverage to a wider area and cheaper to purchase. However, regulations, spectrum deregulation efforts and necessary market incentives may be needed to supplement the technical effort to reduce cost - also for the end user equipment.

Ultimately, the services delivered via the $5 \mathrm{G}$ Wi-fi networks should be relevant to the people living in these unserved. This will call for a lot of user experience, and interaction design research. 


\section{Methodology}

In the bid to understand the potential of Community Based Networks in the delivery of telecom networks, the Grounded Theory was adopted as a tool. This is an inductive approach of generating a theory or hypothesis from data [34]. Data is gathered via interviews and documentents. The data gathered are coded to identify concepts in words, phases and sentences. Theoretical sampling is performed on the codes via various forms of categorization until theoretical saturation is achieved [33]. There are various theoretical sampling techniques, such as the Strauss and corbin Tradition, the Chalmers tradition and Glazer and Strauss Tradition among others [2]. Using this tool, data gathered from the 6 cases via qualitative interviews, were coded and generalization identified. The coding process involved, the open axial and selective coding processes guided by the Strauss and Corbin tradition of Grounded Theory [33]. The open coding involved, concept identification coding. The axial coding involves the grouping of codes into categories (cross coding). The selective coding involves the process of theorizing and generalizing around the core concept. The theorization for each case involved the search of events that led to action and interactions. These interaction resulted in the implementation of the infrastructure in each case.

This process was carried for the individual cases. The six cases were then separated into two categories. These were the developed and developing country cases as seen in the table below.

Further theorizations were carried out by cross-coding the outcome of the selective coding of each case. The aim was to find common events (causalities) that led to actions and interactions. These actions resulted in the implementation of the infrastructure in each context.

Table 1

\begin{tabular}{lll}
\hline & \multicolumn{2}{c}{ Cases } \\
\cline { 2 - 3 } & Developed Country Cases & Developing Country Cases \\
\hline 1 & $\begin{array}{l}\text { Hallaryd Broadband Cooperative } \\
\text { (Sweden) }\end{array}$ & $\begin{array}{l}\text { Johannesburg Wireless User Group } \\
\text { (South Africa) }\end{array}$ \\
2 & $\begin{array}{l}\text { Magnolia Road Internet Cooperative } \\
\text { (USA) }\end{array}$ & Dharamsala Wireless Network (India) \\
3 & Djurslandsnet (Denmark) & Ghana Wireless Project (Ghana) \\
\hline
\end{tabular}

Source: Williams, 2015. 


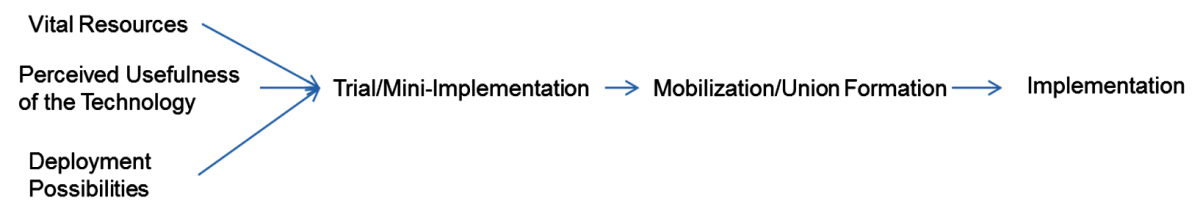

Figure 1 CBNM model for developed countries.

Source: Williams, 2015.

\section{Findings}

The resulting models were various forms of Community Based Networks Mobilization Models (CBNM). The CBNMs were categorized into two contexts. The first context developed country context, while the second context was the developing country context.

\subsection{CBNM Model for Developed Countries}

The figure above represents the CBNM model for the developed country cases. The model illustrates the process Community Based Networks undergo to facilitate telecom/broadband infrastructure and service delivery. In developed countries the Community Based Networks emerged if the following factors exist:

- The vital resources.

- Deployment possibilities.

- The usefulness of the service.

As identified in the Section 2, the usefulness of the service plays a huge role in the adoption of telephony and Broadband by Community Based Networks. Nevertheless the usefulness of the service was the only reason for deciding to facilitate the infrastructure. The existence of the Vital resources and the deployment possibilities were crucial. The crucial nature of the deployment possibilities stemmed from the fact that the Community Based Networks - in most cases - did not outsource infrastructure deployment.

The vital resources are context unique resources available to the Community Broadband Network. These resources could be inherent resources such as technical knowledge, inherent fabrication skills, financial resources, human resources, technical resources, self-determination and many other contextual factors.

Once the founders or the leaders of the Community Based Networks realized that they had the necessary vital resources, they embarked on searching for deployment possibilities. In some of these areas, they face 


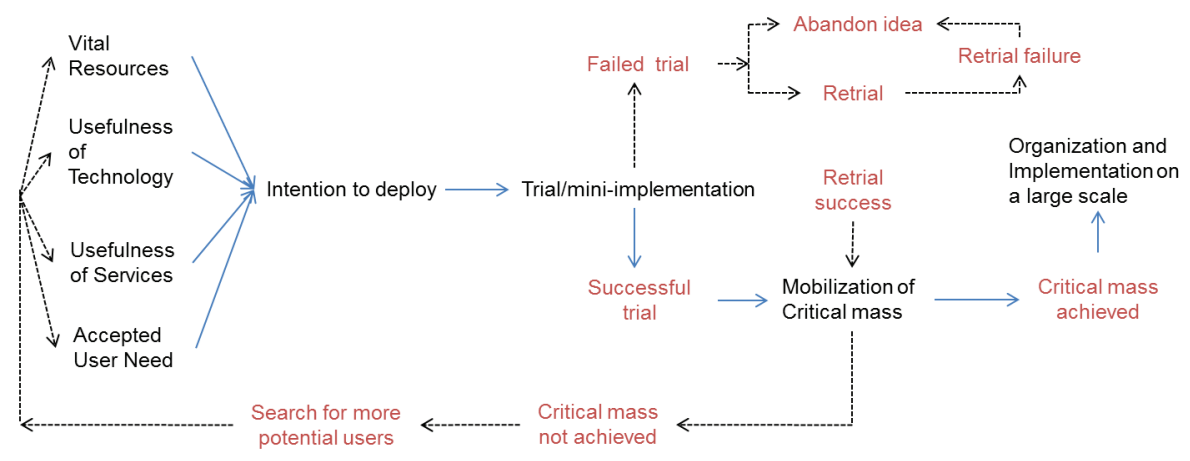

Figure 2 CBNM loop for developing countries.

Source: Williams, 2015.

topographical challenges. Hence "natural base stations" such as hilltops, roof tops and elevated planes were deployed to relay the wireless signals over a large coverage area. In this manner the Capital Expenditure (CAPEX) for such projects is reduced as the community spends less amount of money in purchasing towers.

The existence of these three factors resulted in the Community Based Networks either:

- Perform more tests to ensure the capacity to deploy and sustain the network before proceeding to mobilize members.

- Mobilize members, if they believe that they have the capacity to deploy the network and sustain it.

- Mobilize members to raise an economy to sustain the trials and implementations.

One would say; in the developed countries the users are already aware of the services. In these areas they also have access to supplementary and complementary services.

\subsection{CBNM Model for Developing Countries}

The figure above represents the CBNM model for the developing country cases. The developing country cases were facilitated by early adopters or enthusiasts. These enthusiasts had to carry out some form of trial or experiments with the network. Once they are satisfied with the performance, they showcase their work. The exhibition enables neighbors, friends, etc. to examine the network. In this process, the people visiting the exhibition will identify: 
- The vital resources.

- The usefulness of the technology.

- The usefulness of the service.

- The actual usefulness of the service.

These four factors as seen in the figure above facilitated the intention to deploy the technology by the Community Based Networks. The intention to deploy was identified based on the fact that the need to form Community Based Networks in developing countries was not a conscious event. Rather, it was an accidental activity.

Rather than proceed to implement, the early enthusiasts and early converts needed to conduct trials on a larger scale. This was an exhibition aimed at attracting more members. This was necessary as the enthusiasts needed to facilitate an economy to develop a larger network. A successful exhibition resulted in the sharing of the business model idea, as well as proving that the four factors exist. If the four factors existed and the business model was right, more people were compelled to sign up. This iteration continued until an economy was built and an organization established to facilitate the network. The resulting set of models is seen in the figure below.

The reason for the difference in the structure of both models lies on the earning ability between people in developed and developing countries. In the course of the research, it was realized that finance was not an issue for the developed country cases. But in the developing country cases, they had no financial ability, hence the growth of the network was dependent on the number of members contributing to the community network. This also determined the size of the network.

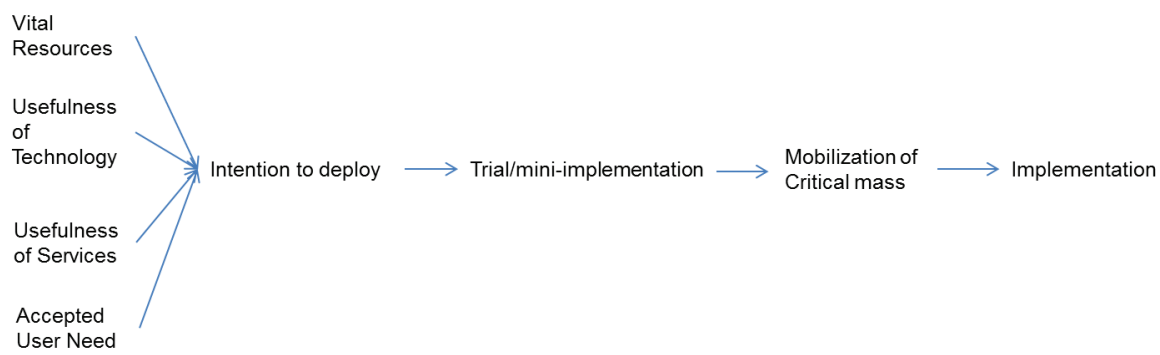

Figure 3 CBNM model for developing countries.

Source: Williams, 2015 


\section{Discussion}

Community Broadband Networks do possess a great deal of potential for the facilitation of $5 \mathrm{G}$ infrastructure and services. The findings in this paper points to the possibility of Community Based Networks deploying 5G if it is useful and they have the resources for the network. Hence, in the development of 5G standards, there ought to be room for these networks.

It is natural for standards being developed to target existing network operators. However, the downside of this approach is the possibility of leaving rural areas behind. Hence the usefulness of $5 \mathrm{G}$ should not be seen only in the context of urban areas, but also in the context of rural areas.

The proposal of WLANs delivering $5 \mathrm{G}$ data rates, which is a standard that may be of use to Community Based Networks, is noble. This is because in most parts of the world - there is extensive fiber optic development. Community Based Networks can access capacity from these fiber optic networks for their $5 \mathrm{G}$ networks.

Wi-Fi over fiber optic connectivity is not a new innovation. Hence, from a path dependency - point of view - this can be extended towards the deployment of 5G Wi-Fi. Although this possibility exists, as mentioned earlier in Section 2, there should be incentives that would trigger the CBNM Models. Such incentives include:

- Affordable cost of sensors and infrastructure equipment.

- The potential to fabricate the Wi-Fi Access point equipment.

- The sustenance of Wi-Fi deregulation in many countries.

- The deregulation of Wi-Fi in countries that are yet to do so.

- The recognition of Community Based Networks as valid players in the market.

Although this section of the paper seems to tout the usefulness of $5 \mathrm{G}$ Wi-Fi, there should be competing WLAN or Wireless Wide Area Network (Wireless WAN) and Wireless Metropolitan Area Networks (Wireless MAN), designed for small network operators. In the development of previous Wireless standards, Wireless WAN and Wireless MAN networks had been designed for traditional telecommunication network operators. If the operators of Community Based Networks can learn about the 802.11 standards and deploy it, they may as well learn about other standards and deploy it as well.

This act will not only validate the Community Based Networks as telecom carriers, but it will establish a new player in the market, that has the potential of extending coverage into the rural areas. The challenge $5 \mathrm{G}$ might face, if one looks back at the trend of Wireless Network deployment, globally, it is 
clear that attaining Universal Access of $3 \mathrm{G}$ and $4 \mathrm{G}$ networks is an uphill task for the market. It will be unwise to assume that this may not be the case of 5Gthough it is a wireless network with a different architecture and intelligence. Hence, identifying new market players in the $5 \mathrm{G}$ ecosystem is important. But these market players will only join the market, if their interests are met. This paper suggests such a player, that should not be ignored.

\section{Conclusion}

This paper was designed to discuss the potential relationship between Community Based Networks and 5G diffusion and adoption. The Community Based Network (CBNM) Models were introduced in this paper. These models showcased factors that led Community Based Network to implement Broadband infrastructure. The CBNM models for developing countries indicate that Community Based Network in developing countries can develop telecom infrastructure if they have the vital resources, they know the usefulness of the service, the usefulness of the relationship and the actual usefulness of the service to them. The CBNM models for developed countries indicates that Community Based Networks will develop the intention to deploy the telecom infrastructure and eventually deploy the infrastructure, if they have the vital resources, they know the usefulness of the technology and they are aware of the deployment possibilities.

Based on the findings, this paper concludes that the rural development of $5 \mathrm{G}$ is possible using the vehicle of the Community Based Networks. However, from the standard development point of view, the so called 5G Wi-Fi should be promoted. The paper also proposes the development of affordable Wireless MAN and Wireless LAN standards to aid Community Based Networks. From the regulatory point of view, Wi-Fi should still be deregulated. Wireless MAN and Wireless WAN spectrum for Community Based Networks should be deregulated. From the economic point of view, and the 5G equipment for Community Based Networks should be affordable and accessible.

In this manner, the coverage of 5G, especially in developed countries may be significant, compared to earlier wireless Generations of standards.

\section{Acknowledgment}

Special Thanks to Prof. Knud Erik Skouby, Director, CMI, Aalborg University, Assoc Prof. Morten Falch, Assoc. Prof Reza Tadayoni and Prof. Anders Henten. All from CMI Aalborg University. 


\section{References}

[1] Yardley, M. (2012). "Developing successful Public-Private Partnerships to Foster Investment in Universal Broadband Networks," in Regulatory and Market Environment Division of the Telecommunication. ITU Publication.

[2] Williams, I. (2015). Analysis of Public Private Interplay Frameworks in the Development of Rural Telecommunications Infrastructure: A MultiCase Study. Aalborg: Aalborg University Press.

[3] Kakekaspan, M., O'Donnell, S., Beaton, B., Walmark, B., and Gibson, K. (2014). The first mile approach to community services in fort servern first nation. J. Community Inform. 10(2).

[4] Siochrú, S. O., and Girard, B. (2005). Community-Based Networks and Innovative Technologies: New Models to Serve and Empower the Poor. UNDP Report. Geneva: UNDP.

[5] Salemink, K., and Bosworth, G. (2014). Investigating Community-Led Broadband Initiatives as a Model for Neo-Endogenous Development. Paper Presented at 12th Rural Entprepreneurship Conference, Newport.

[6] Wang, T., Li, G., Ding, J., Miao, Q., Li, J., and Wang, Y. (2015). "5G spectrum: is china ready?" in Proceedings of the IEEE Communications Magazine (Rome: IEEE), 58-65.

[7] 5GPP. (2014). The 5G Infrastructure Public Private Partnership. Available at: https://5g-ppp.eu/ [accessed February 24, 2016].

[8] METIS 2020. (2015). The METIS 2020 Project. Available at: https://www.metis2020.com/ [accessed February 24, 2016].

[9] Boccardi, F., Heath, R. W., Lozano, A., Marzetta, T. L., and Popvski, P. (2014). "Five disruptive techology directions for 5G," in Proceedings of the Communications Magazine (Rome: IEEE), 52(2), 74-80.

[10] RTV Noord. (2015). North Groningen Gets Incredible Fast Mobile Internet. Available at: http://www.rtvnoord.nl/nieuws/152709/ Noord-Groningen-krijgt-onvoorstelbaar-snel-mobiel-internet [accessed February 24, 2016].

[11] Mack, E. (2016). How Virizon Is Testing Blazing-Fast 5G Mobile Datafor a Planned 2017 Launch. Available at: http://www.gizmag.com/verizonwireless-5g-lte-a-testing/41993/ [accessed February 24, 2016].

[12] Yin, J., Mao, Y., Leng, S., Wang, X., and Fu, H. (2015). "QoE provisioning by random access in next-generation wireless networks," in Proceedings of the 2015 IEEE Global Communications Conference (GLOBECOM) 6-10 December 2015 (San Diego, CA: IEEE), 1-7. 
[13] Almasi, B. (2015). "A solution for changing the communication interfaces between WiFi and 3G without packet loss," in Proceedings of the 38th International Conference on Telecommunications and Signal Processing (Prague: IEEE), 1-5.

[14] Abbas, N., and Saade, J. (2015). "A fuzzy logic based approach for network selection in WLAN/3G heterogenous network," in Proceedings of the 12th Annual IEEE Consumer Communications and Networking Conference (CCNC) (Las Vegas, NV: IEEE), 631-636.

[15] Xiaoyu, W., Weiliang, Z., Xiaolong, G., Chunshan, X., Miao, F., and Junwei, W. (2012). Future Smart Phone Solution White Paper. Shenzhen: Huawei.

[16] Shana'a, O. (2013). Cellular vs. WiFi: future convergence or an utter divergence? Panel discussion at Radio Frequency Integrated Circuits Symposium (RFIC) (Rome: IEEE), I-II.

[17] 3 Mobile. (2015). Huawei E5573 4G Mobile Wi-Fi. Available at: http:// www.three.co.uk/Discover/Devices/Huawei/E5573_4G_Mobile_Wi-Fi? memory=0andcolour=White [accessed March 06, 2016].

[18] Aboul-Magd, O., Kim, J., Wentink, M., Yang, D., and Stacey, R. (2015). Status of Project IEEE 802.11ac. (Rome: IEEE).

[19] Ngo, D. (2012). 5 G Wi-Fi (802.11ac) Explained: It's Cool. San Francisco, CA: CNET.

[20] Fitchard, K. (2012). Wi-Fi Alliance gobbles up WiGig; Plans to Certify Devices This Year. Available at: https://gigaom.com/2013/01/03/wi-fialliance-gobbles-up-wigig-plans-to-certify-devices-this-year/ [accessed June 03, 2016].

[21] Fitchard, K. (2014). Are You Ready for the Next Chapter of Wi-Fi? Meet 802.11ax. San Francisco, CA: Gigaom. Available at: https://gig aom.com/2014/06/12/next-phase-of-wifi-80211ax/ [accessed March 6, 2016].

[22] Ziewitz, M., and Brown, I. (2013). "A prehistory of Internet Governance", in Research Handbook on Governance of the Internet, eds. I. Brown (Oxford: University of Oxford Press), 3-26.

[23] Lehr, W., Sirbu, M., and Gillett, S. (2006). Wireless is changing the policy calculus for Municipal Broadband. Gov. Inf. Q. 23, 435-453.

[24] Finquelievich, G., and Kisilevsky, G. (2005). Community democratization of telecommunications community cooperatives in Argentina: the case of TELPIN. J. Commun. Informat. 1.

[25] Brooke, T. (2014). About us. Available at: http://brooketel.ca/about/ [Accedded May 8, 2014]. 
[26] Adams. (2014). About us. [Available at: http://www.adams.net/ [Accessed May 8, 2014].

[27] Viardot, E. (2013). The role of cooperatives in overcoming the barriers to adoption of renewable energy. Energy Policy, 63, 756-763.

[28] Oost, E. V., Verhaegh, S., and Oudshoorn, N. (2007). From Innovation Community to Community Innovation: User-initiated Innovation in Wireless Leiden. Sci. Technol. Hum. 20.

[29] Shaffer, G. (2013). "Lessons learned from grassroots wireless networks in Europe," in Social and Economic Effects of Community Wireless, ed. A. Abdelaal (Hershey: IGI Global), 236-254.

[30] Picot, A., and Wernick, C. (2007). The role of government in Broadband Access. Telecommun. Policy 31, 660-674.

[31] Strover, S., and Mun, S. (2006). Wireless broadband, communities, and the shape of things to come. Gov. Inf. Q. 23, 348-358.

[32] Tapia, A., Maitland, C., and Stone, M. (2006). Making IT work for municipalities: building municipal wireless networks. Gov. Inf. Q. 23, 359-380.

[33] Strauss, A. L., and Corbin, J.M. (1998). Basics of Qualitative Research: Techniques and procedures for Developing Grounded Theory. New Delhi: Sage Publications.

[34] Glazer, B. (1992). Basics of Grounded Theory Analysis: Emergence vs. Forced. Mill Valley, CA: Sociology Press.

\section{Biographies}

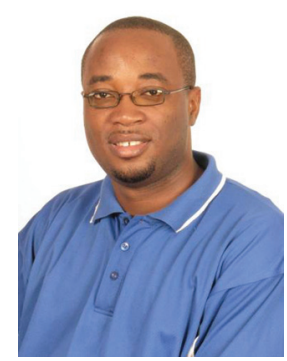

I. Williams is an Adjunct lecturer at Center for Communication, Media and Information Technologies (CMI) located at Aalborg University Copenhagen. He holds a Bachelor in Physics, a Master degree in Information and Communications Technologies and a Ph.D. He has since 2010 researched into 


\section{I. Williams}

socio-economic, socio-technical related to Information and Communications Technologies. His main research focus however is in the facilitation of telecom infrastructure using Public Private Partnerships.

He has authored more than 20 research publications, including journal papers, books, book chapters, conference papers and magazine articles. He is the co-editor of the Book, The African Mobile Story. He has organized conferences like the CMI annual conference and the CMI/GTUC conferences. 